\title{
Relationship between Technological Capacity, Innovation Outcome and Business Performance of Small and Medium Enterprises in Ho Chi Minh City, Vietnam
}

\author{
Thu Diem Le, MSc' ${ }^{1}$, Vu Thi Phuong Giang ${ }^{2}$ \\ ${ }^{I}$ Southerm Institutes of Social Sciences, Ho Chi Minh city, Vietnam \\ ${ }^{2}$ Ministry of Science and Technology, Hanoi city, Vietnam
}

*Corresponding Author: MSc. Thi Phuong Giang Vu; NOIP, Ministry of Science and Technology, Hanoi city, Vietnam.

\begin{abstract}
This research concerns the impact that technological capacity has on the innovation outcome and business performance of small and medium-sized enterprises (SMEs), using transfer path analysis to accredit the relationship among technological capacity, innovation outcome and business performance of SMEs.In correlation with reviewed literatures, positive correlation among the three notions is confirmed with a significance of $5 \%$ (or $95 \%$ credibility). To be more specific, technological capacity has positive impact, both directly and indirectly (via innovation outcome) on business performance. As a consequence, this allows SME managers to improve innovation outcome and business performance through the enhancement in technological capacity and managing effective innovation procedure. In addition, this research proposes possible supporting policies to the government such as technological investment aids, technological training aids, financial aids, and technology and business incubator for SMEs.
\end{abstract}

Keywords: Technological capacity, innovation outcome, business performance, small and medium enterprises in HCM city

\section{INTRODUCTION}

Innovation is deemed the motivation for economic growth and competitiveness against other nations. Specifically, on the scale of an enterprise, this activity creates crucial competitive edge due to reduced manufacturing cost when applying new technology and diverse marketing approaches when introducing business models or new unique products to customers. As a consequent, innovation has always been a central issue to enterprises; however, the scale of innovation of any form depends largely on the technological capacity of each individual enterprise, and this capacity is indeed the prerequisite for innovation.

\section{Data And Research Methods}

This research uses quantitative methods, questionnaires, five-point Likert scale and conducts a survey on 100 enterprises of different industries in Ho Chi Minh City. The study subjects are small and medium enterprises, with information collected from middle and senior managers. Among 100 enterprises, the structure is as follows: (1) By industry: Enterprises in industries of Mechanics, Electronics, Chemistry and Substances - Rubber - Plastics and Food-Food Processing account for $16 \%, 26 \%, 29 \%$ and 29\%, respectively; (2) By size: Small enterprises account for $25 \%$, while medium enterprises account for 75\%; (3) By level of management: Middle managers account for 75\% and senior managers account for 25\%; (4) By operation time: $13 \%$ of enterprises have less than 10 years of operation, $24 \%$ of enterprises have 10 to under 20 years and $54 \%$ of enterprises have more than 20 years of operation.

Research method: The research is carried out in 2 steps: (1) Preliminary research by building a scale based on opinions of experts in product research, development and innovation, along with synthesis of relevant theoretical bases in order to make suitable observed variables; (2) Official research, using SPSS 20.0 for univariate and multivariate descriptive statistics to test the reliability of the scales and the correlation coefficient of the total variable. Next, the Cronbach's Alpha-based scale test is 
included in exploratory factor analysis (EFA) and linear regression analysis to determine each factor and its impact. After that, Path Analysis technique is used to determine the direct and indirect effects on the dependent variable via the independent variable.

\section{THEORIES AND RESEARCH FRAMEWORK}

\subsection{Relationship between Technological Capacity, Innovation Outcome and Business Performance}

Technological capacity represents an enterprise's capacity to use diverse scientific and technological resources to develop ideas for viable, unique and useful new products in the market, thereby promoting rapid growth for the enterprise and creating a premise for competitive advantages (Fernande-Messa, 2014). The concept of technological capacity includes not only investment in innovation-oriented $\mathrm{R} \& \mathrm{D}$, but also the application of scientific and technological advances that improve products, or technological processes in production. Thus, once new technological knowhows are pursued to apply in production, they become a knowledge asset, which is of great importance to enterprises.

Innovation normally starts with research and development (R\&D) activities to improve or apply modern technologies to create new, unique and useful products to meet the continuously changing needs of the market. This process requires enterprises to have financial resources as well as other resources for planning, implementing research, or testing products, etc. Meanwhile, SMEs are often constrained in finance and other resources, so they often have open and innovative approaches to take advantage of external knowledge to use in different appropriate forms such as patenting an invention or applying expired inventions to create new products. The open innovation process allows SMEs to combine internal and external technological knowledge, thereby increasing the efficiency of production and business activities, such as reducing costs, accelerating product introduction process, making unique and useful products, cutting production costs, continuously introducing new products to the market, etc. Thus, enterprises can gain positive business performance (Chesbrough, 2017).

However, knowledge mining is only effective when enterprises have compatible technology capacity to quickly grasp opportunities, properly appreciate the value brought by modern technology and master new technologies in production practice to successfully create and commercialize new products of good quality and value (Srivastava et al., 2015). From there, enterprises can expand market share, increase sales, raise brand awareness, etc. or in other words, improve business performance. Therefore, which enterprises possess higher technological capacity will better identify, grasp, and exploit external knowledge to gain innovation outcome and better business performance. There are 2 hypotheses as follows:

- H1: Technological capacity has a positive impact on innovation outcome.

- H2: Technological capacity has a positive impact on business performance.

\subsection{Relationship between Innovation Outcome and Business Performance}

Business practice shows that SMEs are always flexible and quick in response to changing need, thanks to their close relationship with customers. Thus, the outside-in open innovation will help these enterprises gain new opportunities and enhance their creative problem-solving capacity through exploitation of external knowledge from stakeholders, especially customers, to supplement internal knowledge to make their businesses more creative and innovative. Absorbing external knowledge from different sources help enterprises achieve positive innovation outcomes such as improved product features, new products and shorter time to market, thereby driving growth, sales, profits as well as brand awareness. In other words, innovation outcome has an impact on business results.

According to previous studies, the relationship between innovation outcome and business performance is positive(Chiaroni et al., 2009; Reed et al., 2012), therefore, this research hypothesize that open innovation will reduce costs, shorten products' time to market (TTM), increase sales, and improve technology capacity, thus positively impacting business performance. The hypothesis is as follows:

- H3: Open innovation has a positive relationship with business performance. 
Relationship between Technological Capacity, Innovation Outcome and Business Performance of Small and Medium Enterprises in Ho Chi Minh City, Vietnam

\subsection{Impact of Business Size on Business Performance}

Besides the impact of technological capacity and innovation outcome, several control variables such as the enterprise's age, industry, size, etc. are also considered to have an influence on enterprises. The size is considered as one of the important factors that greatly influences the formation of technological capacity, thereby having a strong impact on innovation outcome and business performance. Especially, its impact on economic efficiency has been proven (Sin, 2005). Thus, the next hypothesis that we will examine in this research is:

- H4: There is a significant difference in business performance between small enterprises and medium enterprises

The relationship between technological capacity, innovation outcome, business size and business performance are shown in the research framework.

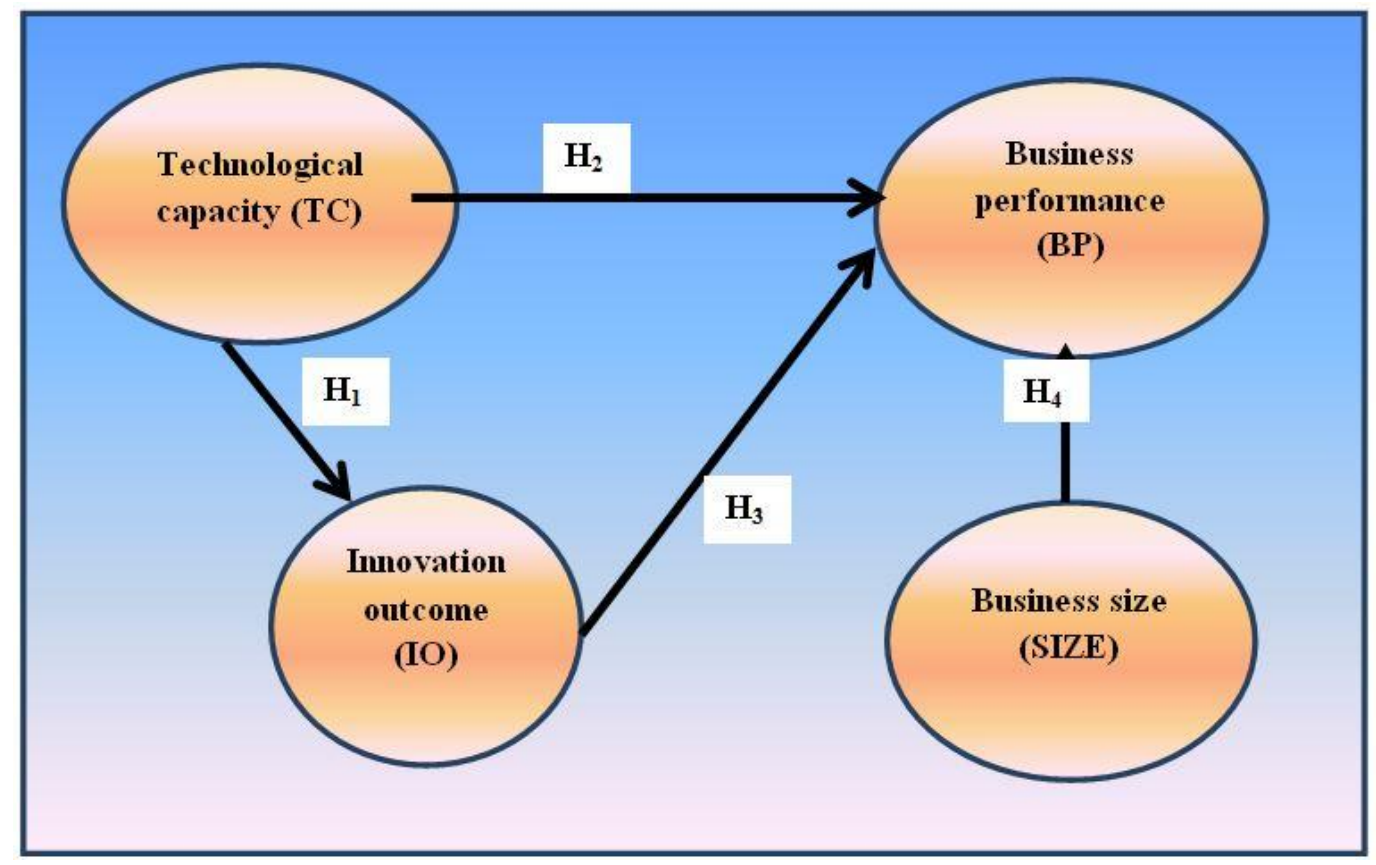

Figure1. Research framework

\subsection{Measurement of Research Concepts}

Technological capacity (TC) is measured by 5 components including: application of new technology; resources used for innovation; institutionalization of innovation process; participation of departments in innovation; and employees' participation in proactively suggesting ideas. Innovation outcome is measured by 5 components according to the authors' measurements (Sin, 2005): the products' commercialization, novelty and originality, time to market, improvement in quality and enterprises' frequency of introducing new products. Business performance (BP) is measured by operating results and financial results, which in this research are proposed based on previous studies (Kim and Lee, 2010), including market share, market share growth rate, brand adoption, sales growth, return on asset, profit margin and sales growth rate to total sales of new products. The concept of size is classified into 2 groups: small size and medium size, then encoded into Value 1 and Value 2, respectively. The five-point Likert scale is used to measure the current situation of enterprises in terms of technological capacity, innovation outcome and business results, including 17 components as shown in Appendix 1: Measurement of research concepts. (See appendix 1).

\section{Hypothesis Testing And Results}

\subsection{Exploratory Factor Analysis and Reliability of the Measurement Reliability Testing}

Results from exploratory factor analysis (EFA) to examine the value of observed variables in measuring the research concepts for independent variables "Technological capacity - TC", "Innovation Outcome - IO" and dependent variable "Business Performance - BP" (see Appendix 2A) 
have shown that there are 2 factors extracted from the set of 10 observed variables designed to measure "TC" and "IO" (The eigen values of these 2 factors are greater than 1, thus satisfying the conditions of the extracted factors) and both factors explained $68.47 \%$ of the total variation of 10 variables (above the required minimum value of 50\%).

Similarly, only 1 factor extracted from 7 observed variables is designed to measure the concept of "BP" (only 1 factor with eigen value greater than 1 - see Appendix 2B). This factor explained 68.94\% of the total variation of 7 observed variables. The KMO test shows that all necessary conditions for analysis are satisfied, as both cases have the value of 0.82 and statistical reliability at $95 \%$ (Hair, 2006).

The results of EFA also confirms that all 5 observed variables measuring "TC" and 5 observed variables measuring "IO" can measure the above 2 concepts as their factor weights (representing the correlation coefficient of the observed variable with the factor) are greater than 0.3 (Hair, 2006) and this weight is higher when they measure the concept that each of them is designed to measure, thus 5 observed variables (TC1 to TC5) are valuable in measuring the concept of "TC" and the 5 observed variables (IO1 to IO5) are valid in measuring the concept of "IO" (Appendix 2A). Analysis of the factor weights of 7 observed variables measuring "BP" also gives similar results as these weights are all greater than 0.3 and they are completely valid in measuring this concept (Appendix 2B).

The result of reliability analysis (Appendix 3) also shows that the Cronbach's alpha coefficient used to measure all 3 concepts is larger than the required minimum of 0.7 for Quantitative research (Hair, 2006). Moreover, removing any of the observed variables does not increase the Cronbach's alpha coefficient, so all the components are reliable in measuring the total variables (TC, IO and BP), and the value of these variables ("TC", "IO" and "BP") will be determined by the average of the components.

Simple statistical analysis calculating thee mean value, variability and correlation coefficient of the variables shown in Table 1 below show that: (1) All enterprises rated their current state of technological capacity, innovation outcome and business performance as nearly good (the average value of the 3 variables is $3.70,3.99$ and 3.96, respectively, corresponding to the percentage of $74 \%$, $78 \%$ and $79 \%$ ); (2) The standard deviations of research variables are low compared to the average value $(16 \%, 20 \%$ and $17 \%$ compared to the average of all 3 variables TC, IO and BP, respectively), due to which the dispersion of the data is not high; (3) the values of the variables are guaranteed for normal distribution, so there is no need to convert the data to normal distribution [Normal distribution will appear when the skewness and kurtosis of the distribution equal 0 , but the acceptable range for skewness is $(-1,+1)$ and for kurtosis is $(-2,+2)]$; (4) The correlation coefficient of the independent variables is high, but not to the extent that may cause the effect of multicollinearity (The multicollinearity will be high and needs to be resolved when the correlation between 2 independent variables is $80 \%$ and above (Hair, 2006)). On the other hand, IO is not only an independent variable of BP but also a dependent variable of TC, so although the correlation relationship is strong, it is only between dependent variable and independent variable, and there is no need to test for multicollinearity before constructing the linear correlation function.

Table1. Variation and correlation coefficients between research variables

\begin{tabular}{|l|r|r|r|r|c|c|c|}
\hline Research variables & Average & Standard Deviation & Skewness & Kurtosis & \multicolumn{3}{|l|}{$\begin{array}{l}\text { Correlation } \\
\text { coefficient }\end{array}$} \\
\cline { 4 - 8 } & & & & & TC & IO & BP \\
\hline $\begin{array}{l}\text { Technological capacity } \\
\text { (TC) }\end{array}$ & 3.70 & 0.60 & -0.51 & 0.06 & 1.00 & $0.54^{*}$ & $0.56^{*}$ \\
\hline Innovation Outcome (IO) & 3.88 & & & & & & \\
\hline Business Performance (BP) & 3.96 & 0.80 & -0.78 & 0.62 & & 1.00 & $0.61^{*}$ \\
\hline
\end{tabular}

(Data is calculated from 100 questionnaires; The symbols are as follows: ":sufficient statistical reliability of $95 \%$;Kurtosis: kurtosis of the distribution; Skewness: skewness of the distribution).

\subsection{Hypothesis Testing}

\subsubsection{Model's Suitability Testing}

The research model in Figure 1 is a linear model that shows direct and indirect effects of the variable "Technological capacity" on the variable "Business Performance" via the intermediate variable 
"Innovation Outcome", specifically as follows: The dependent variable BP (Business Performance) is affected by 2 independent variables, TC (Technological capacity) and IO (Innovation Outcome), but $\mathrm{IO}$ is also acts as an intermediate variable affected by the dependent variable TC; Thus, TC will directly affect BP and indirectly affect the dependent variable BP via the intermediate variable IO. The linear model is expressed through 2 standardized correlation functions (functions with a $\mathrm{Z}$ distribution with mean value 0 and variance 1 ) as follows:

$$
\begin{aligned}
& \mathrm{E}\left(\mathrm{Z}_{\mathrm{IO}}\right)=\beta_{\mathrm{TC} . \mathrm{IO}} * \mathrm{Z}_{\mathrm{TC}}(1) \\
& \mathrm{E}\left(\mathrm{Z}_{\mathrm{BP}}\right)=\beta_{\mathrm{TC} . \mathrm{BP}} * \mathrm{Z}_{\mathrm{TC}}+\beta_{\mathrm{IO} . \mathrm{BP}} * \mathrm{Z}_{\mathrm{IO}}(2)
\end{aligned}
$$

(Note: $\beta_{\mathrm{TC} . I O}$ represents the standardized regression weight of the independent variable TC with dependent variable IO; $\beta_{\mathrm{TC} . \mathrm{BP}}$ is the normalized regression weight of the independent variable TC with dependent variable BP; $\beta_{\mathrm{IO} . \mathrm{BP}}$ is the standardized regression weight of the independent variable TC with the dependent variable $\mathrm{BP}$ ).

In the structural model, the coefficient of determination $\mathrm{R}^{2}$ (or so-called the composite reliability value) of the model is determined as follows:

$\mathrm{R}^{2}=1-\left(1-\mathrm{R}_{1}{ }^{2}\right)\left(1-\mathrm{R}_{2}{ }^{2}\right) \ldots\left(1-\mathrm{Ri}^{2}\right)$ (3) ( $\mathrm{i}$ is the number of multivariate correlation equations in the model) and in this case the model only has 22 correlation functions, so the coefficient of determination $R^{2}=$ $1-\left(1-\mathrm{R}_{1}^{2}\right)\left(1-\mathrm{R}_{2}^{2}\right)$.

The multivariate regression analysis of 2 standardized regression functions (1) and (2) shown in Table 2 indicates that the standardized regression functions of dependent "Innovation Outcome" (IO) according to the independent variable "Technological capacity" (TC) has a coefficient of determination of the linear correlation model at $37 \%$ (R1). This coefficient indicates the independent variable TC explains $37 \%$ of the total variation of dependent variable IO. The standardized regression functions of dependent variable "Business Performance - BP" according to independent variables TC and IO shows that the coefficient of determination is $36 \%$, that is, the simultaneous variation of the 2 independent variables explains $36 \%$ of the total variation of the dependent variable.

\begin{tabular}{|c|c|c|c|c|c|c|c|}
\hline \multicolumn{4}{|c|}{$\begin{array}{l}\text { Correlation function 1: Dependent variable IO and } \\
\text { independent variable TC }\end{array}$} & \multicolumn{4}{|c|}{$\begin{array}{l}\text { Correlation function 2: Dependent variable BP and } \\
\text { independent variables TC \& IO }\end{array}$} \\
\hline $\begin{array}{l}\text { Independent } \\
\text { variable }\end{array}$ & $\begin{array}{l}\text { Standardized } \\
\text { regression } \\
\text { coefficient }\end{array}$ & $\mathrm{T}$ value & $\begin{array}{l}\mathrm{P} \\
\text { value }\end{array}$ & $\begin{array}{l}\text { Independent } \\
\text { variable }\end{array}$ & $\begin{array}{l}\text { Standardized } \\
\text { regression } \\
\text { coefficient }\end{array}$ & $\mathrm{T}$ value & $\mathrm{P}$ value \\
\hline TC & 0.61 & 7.68 & 0.000 & TC & 0.37 & 3.59 & .000 \\
\hline \multirow{2}{*}{\multicolumn{4}{|c|}{$\begin{array}{l}\text { Coefficient of determination } \mathrm{R}_{1}{ }^{2}=0.37 ; \mathrm{F}=58.91 \text {, } \\
\text { probability value } \mathrm{P}=0.000 \text { satisfied the statistical } \\
\text { reliability of } 95 \% \text {, showing that there is at least } 1 \\
\text { independent variable affecting the dependent } \\
\text { variable. }\end{array}$}} & IO & 0.31 & 3.08 & .000 \\
\hline & & & & \multicolumn{4}{|c|}{$\begin{array}{l}\text { Coefficient of determination } \mathrm{R}_{2}{ }^{2}=0.36 ; \mathrm{F}=28.75 \text {, } \\
\text { probability value } \mathrm{P}=0.000 \text { satisfied the statistical } \\
\text { reliability of } 95 \% \text {, showing that there is at least } 1 \\
\text { independent variable affecting the dependent variable }\end{array}$} \\
\hline
\end{tabular}

Table2. Linear correlationfunction measuring model standardized coefficient

Although the coefficients of determination for both individual correlation functions are low, in the structural equation modeling (SEM), the total coefficient of determination $\mathrm{R}^{2}$ can most accurately measure the model's suitability, and $\mathrm{R}^{2}=1-\left(1-\mathrm{R} 1^{2}\right)\left(1-\mathrm{R} 2^{2}\right)=[1-(1-0.37)(1-0.36)]=0.597$. Thus, the model with independent variable TC and intermediate variable IO explains $59.7 \%$ of the variation of the dependent variable "BP" and the suitability of the model is acceptable as it explains over $50 \%$ of the total variation of the dependent variable by the variation of the independent variable "TC" and intermediate variable "IO".

\subsubsection{Research Hypothesis Testing}

The results in table 2 show that the P-values corresponding to each t-test for the standardized regression coefficients of independent variable in both functions are smaller than coefficient $\alpha(\alpha$ $=0.05$ ), which determines that variable $\mathrm{TC}$ has an impact on dependent variable $\mathrm{IO}$ in the first correlation function, and both TC and IO have an impact on dependent variable BP in the second correlation function with the reliability of $95 \%$. Thus, the following conclusions are drawn: 
1. The results of the first standardized correlation function $\left(\mathrm{E}\left(\mathrm{Z}_{\mathrm{IO}}\right)=\beta_{\mathrm{TC} . \mathrm{IO}} * \mathrm{Z}_{\mathrm{TC}}=0.61 * \mathrm{Z}_{\mathrm{PM}}\right)$ shows that the dependent "TC" has a positive impact on variable "IO" and the impact of this function is very strong (as the standardized coefficient of the correlation function is 0.61 ). Thus, hypothesis $\mathrm{H} 1$ is accepted (H1: TC has a positive and concurrent impact on IO).

2. The results of the second standardized correlation function $\left(\mathrm{E}\left(\mathrm{Z}_{\mathrm{BP}}\right)=\beta_{\mathrm{TC} . \mathrm{BP}} * \mathrm{Z}_{\mathrm{TC}}+\beta_{\mathrm{IO} . \mathrm{BP}} * \mathrm{Z}_{\mathrm{IO}}=\right.$ $0.37 * \mathrm{TC}+0.31 * \mathrm{IO}$ ) shows that the variable "TC" has a positive and concurrent impact on "BP" with a standardized weight of 0.38 , so hypothesis $\mathrm{H} 2$ is accepted $(\mathrm{H} 2$ : TC has a positive and concurrent impact on BP).

3. Similarly, the results of the second standardized correlation function also shows that the standardized correlation coefficient of independent "IO" and dependent variable "BP" is 0.31 and has sufficient statistical reliability at $95 \%$, so $\mathrm{H} 3$ is also accepted (H3: IO has a positive and concurrent relationship with BP)

The standardized regression coefficient also shows that the variable "TC" has a strong impact on the dependent variable "BP" compared to the variable "IO", with the regression weights of 0.37 and 0.31 , respectively; However, the linear regression weight of the variable "TC" only shows the direct impact, but "TC" also has an indirect impact on "BP" via the intermediate variable "TC", and the indirect impact is determined by $\beta_{\mathrm{TC} . \mathrm{IO}} * \beta_{\mathrm{TC} . \mathrm{BP}}=0.61 * 0.37=0.226$. Thus, the total impact of the variable "TC" on the variable "BP" will be: $0.6\left(\beta_{\mathrm{TC} . \mathrm{BP}}+\beta_{\mathrm{TC} . \mathrm{IO}} * \beta_{\mathrm{TC} . \mathrm{BP}}=0.37+0.226=0.6\right)$, showing that "TC" has a much stronger impact on "BP" compared to the variable "IO".

Table3. Impacts in the structural model

\begin{tabular}{|l|c|l|l|l|}
\hline Impact & Coefficient & Indirect & Total impact & Proven hypothesis \\
\hline TC to IO & 0.61 & None & 0.61 & H1 \\
\hline TC to BP & 0.37 & 0.226 & 0.60 & H2 \\
\hline IO to BP & 0.31 & None & 0.31 & H3 \\
\hline
\end{tabular}

4.2.4.Testing of the difference of "IO" and "BP" between 2 groups of enterprises by size

Testing the difference between BP of 2 groups of enterprises under simultaneous impact of the variable TC and IO on business performance are determined by a function based on the estimated standardized linear correlation function $\mathrm{E}\left(\mathrm{Z}_{\mathrm{BP}}\right)=\beta_{\text {SIZE. BP }} * \mathrm{Z}_{\text {SIZED }}+\beta_{\mathrm{TC} . \mathrm{BP}} * \mathrm{Z}_{\mathrm{TC}}+\beta_{\mathrm{IO} . \mathrm{BP}} * \mathrm{Z}_{\mathrm{IO}}$ and t-test is performed to examine the regression coefficient $\beta_{\text {SIZE. BP }}$ (expressing the difference between BP of medium enterprises and BP of small enterprises in the correlation function with dummy variables, in which small enterprises are selected as the basis); if this value is other than 0 and has sufficient statistical reliability of $95 \%$, we can conclude that medium enterprises will have better business performance than small enterprises.

Table4. Results of the linear standardized correlation function with dummy variable

\begin{tabular}{|c|c|c|c|}
\hline \multicolumn{3}{|c|}{ Correlation function with dependent variable BP and 3 independent variables SIZED, TC and IO } \\
\hline Independent variable & Regression weight & t-value & p-value \\
\hline SIZED & .241 & 2.93 & .004 \\
\hline TC & .288 & 2.84 & .005 \\
\hline IO & .305 & 3.11 & .002 \\
\hline
\end{tabular}

Coefficient of determination $R_{2}{ }^{2}=0.36 ; F=23.52$, probability value $P=0.000$ satisfied the statistical reliability of $95 \%$, showing that there is at least 1 independent variable affecting the dependent variable.

Results from Table 3 show that all 3 variables SIZED, TC and IO have an impact on Business performance with statistical reliability of $95 \%$ because the p-value of the t-test for all 3 variables are smaller than the error rate $\alpha(\alpha=0.05)$; especially, the standardized regression weight $\beta_{\text {SIZE.BP }}=0.241$ is significant at statistical reliability of 95\%) allowing to draw a conclusion that "business performance of medium enterprises is better than that of small enterprises", meaning that hypothesis $\mathrm{H} 4$ is confirmed. Moreover, when the dummy variable is included in the analysis, independent variables such as TC and IO have an impact on dependent variable BP. Thus, H1, H2, H3, and $\mathrm{H} 4$ are all confirmed in this research (see Table 4). 
Relationship between Technological Capacity, Innovation Outcome and Business Performance of Small and Medium Enterprises in Ho Chi Minh City, Vietnam

\section{RECOMMENDATIONS AND SOLUTIONS}

\subsection{Research Results and Research Proposals}

Research results have shown that the hypothesis of a positive and concurrent relationship between technological capacity and innovation outcome has been proven to be as previously concluded in previous studies (Srivastava, 2015); this research also determines that enterprises' technological capacity, especially based on open innovation, has a positive and concurrent relationship with business performance, and this relationship has been confirmed by authors such as Ferreras-Mendez (2015) and Teece (2014); In the end, innovation outcome will create upward momentum in sales, market share, brand awareness or increase financial results such as ROA, profit margin thanks to cost reduction, and make the products innovative and unique to attract customers. In general, the better the innovation outcome, the greater the business performance, and this once again confirmed what has been discovered in studies around the world (Rohrbeck et al., 2008; Chiaroni et al., 2009; Reed et al., 2012).

In addition to confirming the results of previous studies in many countries around the world, this research also explores the direct and indirect relationship between technological capacitywith business performance through innovation outcome of small and medium enterprises in Ho Chi Minh City, especially, technological capacity not only directly but also indirectly affects business performance via innovation outcome, so it is an important premise for innovation activities in enterprises. Thus, to promote and develop the innovation ecosystem in Vietnam, besides frameworks or pillars for the National Innovation System (NIS), policies to support technology competence enhancement for small and medium enterprises should also be developed.

Moreover, the research also contributes to confirm that economies of scale will make business performance better (medium enterprises have better business performance than small enterprises). Thus, supporting small enterprises to transform into medium enterprises is an aspect that the authorities need to pay attention to. Policies supporting enterprises to increase their size can be implemented through investment support programs for access to new technologies, policies to support supply chain linkages, etc., to help enterprises increase the size and access new technologies by becoming suppliers for large companies, especially multinational companies that are investing in Vietnam.

However, the research still has certain limitations such as small sample size or only focusing on Mechanical Engineering, Electronics, Chemicals-Rubber-Plastic and Food Processing, thus its generalization is rather not high. On the other hand, innovation activities are not only about product and technology innovations, but also include organizational, marketing, and business model innovation activities that have not been mentioned in this research. Besides, the impact of support policies on small and medium enterprises have not been mentioned. Those are the shortcomings that need to be addressed by further studies.

\subsection{Solutions to Enhance Technology Competence}

Findings from the research show that enhancing technological capacity is one of the important measures to create a premise or internal force for SMEs to carry out innovative activities. To enhance technological capacity, each enterprise itself needs to implement solutions such as forming an innovation-oriented culture; building an organizational system to facilitate quick response and implementation of new ideas; creating a physical and mental oriented working environment; encouraging learning and creating know-hows in terms of technology and governance of the innovation process. The basic contents of the solutions are as follows:

\section{Forming an Innovation-Oriented Culture}

Leaders need to develop the ability to lead, command and support the formation and development of innovative behavior by giving opportunities for employees to participate in business development activities, encouraging employees to propose and pursue innovative ideas. Leaders should not just simply give order and closely monitor, but also direct employees to go on a defined path. Moreover, participative leadership and open innovation should be incorporated into companies' culture to motivate employees to participate in activities, proactively take initiatives and pursue innovative ideas, which will lead to the enhancement of innovation capacity; 
Relationship between Technological Capacity, Innovation Outcome and Business Performance of Small and Medium Enterprises in Ho Chi Minh City, Vietnam

Facilitating Rapid Adoption, Response, and Implementation of Innovative Ideas

Structures, procedures and organizational elements need to be designed or re-designed to fit internal and external changes, giving the best support to innovative activities. These could include encouraging the formation and development of ideas, creating an appropriate reward system to promote innovation and quick access to information on science and technology, advances in technology, expired patents to find opportunities to exploit new technologies;

\section{Creating a Physical and Mental Oriented Working Environment}

Innovation can only be realized where people are willing to devote their full capabilities, trust, loyalty, and be open-minded, fair and transparent. This can only be achieved in an environment where workers feel they can develop physically and mentally, thereby understand their role and persistently pursue creative ideas and promote their proactiveness in creative and innovative activities;

\section{Forming and Developing know-hows in Technology and Management}

Enterprises need to equip employees with skills and knowledge related to work and solving arising problems from practices, as these are of great importance in the formation of innovative capacity. The skills and knowledge used by employees while solving problem in a creative way will contribute to the formation of technological know-how, management and relationships, which are great resources that create intangible assets associated with employees;

\section{Governance of the Innovation Process}

Good governance will enable small and medium enterprises with limited resources to produce outstanding innovation outcome. Good governance includes planning and managing the portfolio of new products, institutionalizing product development process, and well-organizing innovation projects.

First, managing the portfolio of new products: Includes planning the procedure of bringing new products to the market through product development projects, evaluation, selection and prioritization; willing to drop out projects that are in progress but proven ineffective according to an appropriate set of criteria.

Second, institutionalizing product development process: The development process of new products includes many stages such as pre-feasibility evaluation of new ideas, product concept formation and optimization, technology design and production to create samples and commercialize the product with a marketing program. Ideas may fail at any stage during this process. Therefore, in order to screen out these ideas/projects, enterprises need to institutionalize the stages in the process and establish a set of criteria for each stage to decide whether the idea worth developing or giving up.

Third, organizing product development activities: This is an important step for creating effective innovation outcome, as it helps to allocate resources to product innovation activities in each stage, establish bi-functional organizational structures (both production and $R \& D$ ) with specialized R\&D units to generate innovative outcome and manage product or technology innovation projects.

\subsection{Proposals for the State's Solutions to Support SMEs' Innovation Activities}

The success of innovation activities not only comes from the enterprise's internal efforts (through technology competence enhancing activities and innovation process management) but also from the utilization and exploitation of support policies from the State. Support policies aiming to strengthen innovation capacity of SMEs include:

First, technology policies: The state or state-owned science and technology organizations can implement programs that support technological innovation for SMEs through funding R\&D costs, promoting joint programs between Industries - Universities or Research Institutes - Enterprises to carry out research and development activities to deploy new technologies for SMEs;

Second, financial policies: Such as establishing venture capital funds to invest in technological innovation for SMEs, programs of debt financing and capital from investment and credit funds supported by the government, programs of credit guarantee and recognition of science, technology and innovation for enterprises with effective technological innovation; 
Third, science and technology business incubation policies for SMEs: Innovating technology or creating new, unique and breakthrough products require laboratories, equipment and modern facilities, which SMEs cannot own. Therefore, in order to support enterprises, especially science and technology enterprises, the State needs to offer support policies to select and accept SMEs with viable ideas for new products into science and technology business incubators to provide them with equipment and facilities to create sample products.

Fourth, policies to support science - technology management: The State needs to implement business consulting programs and provide information on science and technology for SMEs, along with policies on training human resources for research and development, managing enterprises' product and technology innovation processes, and providing relevant knowledge about intellectual property market such as forms of intellectual property or how to obtain information on expired patents or industrial solutions, and how to lease and value intellectual property.

\section{CONClusion}

Innovation is always an important factor determining the success of enterprises in the market as it is a source for competitive advantage. To create innovation outcome, enterprises need to form and develop their technological capacity. With limited resources, SMEs must approach open innovation, where the ability to identify, access and exploit external knowledge is considered of great importance to innovation capacity, and this is the approach of the research in examining the relationship between technological capacity, innovation outcome and business performance. Quantitative research has confirmed that among small and medium enterprises in HCM City, a positive relationship between technological capacity, innovation outcome and business performance always exists and compatible with previous studies in the world. This research also has a new finding that technological capacity has a significantly strong impact on business performance of SMEs in HCMC. This finding helps to suggest solutions to enhance technological capacity for managers and necessary policies for enhancing technological capacity in SMEs from policy makers.

\section{REFERENCES}

Chiaroni. D.. Chiesa. V. and Frattini. F. (2009). "Investigating the adoption of open innovation in the biopharmaceutical industry”. European Journal of Innovation Management. Vol. 12 No. 3. pp. 285-305.

Chesbrough. H. (2017). "The future of open innovation: the future of open innovation is more extensive. more collaborative. and more engaged with a wider variety of participants".Research-Technology Management. Vol. 60 No. 1. pp. 35-38

Fernandez-Mesa. A., Alegre. J. and Chiva. R. (2014). "IT competency and the commercial success of innovation".Industrial Management \& Data Systems. Vol. 114 No. 4. pp. 550-567.

Kim. D. and Lee. R.P. (2010)."Systems collaboration and strategic collaboration: their impacts on supply chain responsiveness and market performance".Decision Sciences. Vol. 41 No. 4. pp. 955-981.

Rohrbeck. R.. Ho"lzle.K.andGemu "nden. H.G. (2008). "Opening up for competitive advantage-how Deutsche Telekom creates an open innovation ecosystem". $R \& D$ Management. Vol. 39 No. 4. pp. 420-430.

Reed. R.. Storrud-Barnes. S. and Jessup. L. (2012). "How open innovation affects the drivers of competitive advantage: trading the benefits of IP creation and ownership for free invention".Management Decision. Vol. 50 No. 1. pp. 58-73.

Sin. L.Y.M., Tse. A.C.B., Heung. V.C.S. and Yim. F.H.K. (2005). "An analysis of the relationship between market orientation and business performance in the hotel industry". International Journal of Hospitality Management. Vol. 24 No. 4. pp. 555-577.

Srivastava. M.K.. Gnyawali. D.R. and Hatfield. D.E. (2015). "Behavioral implications of absorptive capacity: the role of technological effort and technological capability in leveraging alliance network technological resources".Technological Forecasting and Social Change. Vol.92No.1. pp. 346-358.

Teece. D.J. (2014). "The foundations of enterprise performance: dynamic and ordinary capabilities in an (economic) theory of firms".Academy of Management Perspectives. Vol. 28 No. 4. pp. 328-352.

Terziovski. M. (2010). "Innovation practice and its performance implications in small and medium enterprises (SMEs) in the manufacturing sector: a resource-based view".Strategic Management Journal. Vol. 31 No. 8. pp. 892-902.

Wu. J. (2014). "Cooperation with competitors and product innovation: moderating effects of technological capability and alliances with universities”.Industrial Marketing Management. Vol.43 No. 2. pp. 199-209. 
Relationship between Technological Capacity, Innovation Outcome and Business Performance of Small and Medium Enterprises in Ho Chi Minh City, Vietnam

\section{APPENDIX}

Appendix1. Measurement of research concepts

\begin{tabular}{|c|c|c|c|}
\hline Concepts & $\begin{array}{l}\text { Author proposing } \\
\text { measurement }\end{array}$ & $\begin{array}{l}\text { Components used to measure the concept (Observed } \\
\text { variables) }\end{array}$ & Code \\
\hline \multirow{5}{*}{$\begin{array}{l}\text { Technological } \\
\text { Capacity } \\
\text { (TC) }\end{array}$} & \multirow[t]{5}{*}{ Terziovski. 2010.} & $\begin{array}{l}\text { 1.Rapid identification and application of modern } \\
\text { technologies }\end{array}$ & TC1 \\
\hline & & $\begin{array}{l}\text { 2.Planning and implementation of technology and } \\
\text { development resources }\end{array}$ & TC2 \\
\hline & & 3.Institutionalization of innovation process & TC3 \\
\hline & & 4.Involvement of departments in innovation & TC4 \\
\hline & & $\begin{array}{l}\text { 5.Employees being allowed to proactively suggest ideas } \\
\text { for improvement }\end{array}$ & TC5 \\
\hline \multirow{5}{*}{$\begin{array}{l}\text { Innovation } \\
\text { Outcome (IO) }\end{array}$} & \multirow[t]{5}{*}{ Sin, 2005.} & 1.Successful commercialization of new products & IO1 \\
\hline & & 2.Products' novelty and uniqueness & $\mathrm{IO} 2$ \\
\hline & & 3.Shorter time to market of products & IO3 \\
\hline & & 4.Frequency of introducing new products & IO4 \\
\hline & & 5.Better quality of new products & IO5 \\
\hline \multirow{7}{*}{$\begin{array}{l}\text { Business } \\
\text { Performance } \\
(\mathrm{BP})\end{array}$} & \multirow{7}{*}{$\begin{array}{l}\text { Kim and Lee. } \\
(2010)\end{array}$} & 1.Market share & BP1 \\
\hline & & 2.Market share growth rate & BP2 \\
\hline & & 3.Brand adoption & BP3 \\
\hline & & 4.Sales growth & BP4 \\
\hline & & 5.Return on assets & BP5 \\
\hline & & 6.Return on sales & BP6 \\
\hline & & 7.New market sales/total sales & BP7 \\
\hline
\end{tabular}

Appendix2A. Exploratory factor analysis (EFA) for 2 independent variables TC and IO

\begin{tabular}{|c|c|c|c|c|c|c|c|c|c|}
\hline \multirow[b]{2}{*}{$\begin{array}{l}\text { Facto } \\
\mathrm{r}\end{array}$} & \multicolumn{3}{|c|}{ Initial Eigen value } & \multicolumn{3}{|c|}{ Average variance } & \multirow{2}{*}{$\begin{array}{c}\text { Observe } \\
\mathrm{d} \\
\text { variable }\end{array}$} & \multicolumn{2}{|c|}{ Factor weight } \\
\hline & $\begin{array}{c}\text { Factor } \\
\text { varianc } \\
\mathrm{e}\end{array}$ & $\begin{array}{c}\% \text { of } \\
\text { total } \\
\text { varianc } \\
\mathrm{e}\end{array}$ & $\begin{array}{l}\text { Cumulativ } \\
\text { e Variance } \\
(\%)\end{array}$ & $\begin{array}{c}\text { Factor } \\
\text { varianc } \\
\text { e }\end{array}$ & $\begin{array}{c}\% \text { of } \\
\text { total } \\
\text { varianc } \\
\mathrm{e}\end{array}$ & $\begin{array}{l}\text { Cumulativ } \\
\text { e Variance } \\
(\%)\end{array}$ & & $\begin{array}{l}\text { Facto } \\
\text { r } 1\end{array}$ & $\begin{array}{l}\text { Facto } \\
\text { r } 2\end{array}$ \\
\hline 1 & 5.39 & 53.95 & 53.95 & 5.39 & 53.95 & 53.95 & PM1 & 0.33 & 0.63 \\
\hline 2 & 1.45 & 14.52 & 68.47 & 1.45 & 14.52 & 68.47 & PM2 & 0.47 & 0.56 \\
\hline 3 & 0.84 & 8.41 & 76.87 & & & & PM3 & 0.28 & 0.75 \\
\hline 4 & 0.69 & 6.87 & 83.74 & & & & PM4 & 0.09 & 0.83 \\
\hline 5 & 0.46 & 4.60 & 88.34 & & & & PM5 & 0.18 & 0.80 \\
\hline 6 & 0.39 & 3.89 & 92.23 & & & & IO1 & 0.85 & 0.27 \\
\hline 7 & 0.35 & 3.50 & 95.73 & & & & $\mathrm{IO} 2$ & 0.91 & 0.15 \\
\hline 8 & 0.20 & 1.97 & 97.70 & & & & IO3 & 0.85 & 0.24 \\
\hline 9 & 0.15 & 1.52 & 99.22 & & & & IO4 & 0.76 & 0.27 \\
\hline 10 & 0.08 & 0.78 & 100.00 & & & & IO5 & 0.80 & .284 \\
\hline
\end{tabular}

KMO test value $=0.82$, statistical reliability of $95 \%$

Appendix2B. Exploratory factor analysis (EFA) for dependent variable BP

\begin{tabular}{|c|c|c|c|c|c|c|c|c|}
\hline \multirow[b]{2}{*}{ Factor } & \multicolumn{3}{|c|}{ Initial Eigen value } & \multicolumn{3}{|c|}{ Average variance } & \multirow{2}{*}{$\begin{array}{l}\text { Observed } \\
\text { variable }\end{array}$} & \multirow{2}{*}{$\begin{array}{c}\text { Factor } \\
\text { weight }\end{array}$} \\
\hline & $\begin{array}{c}\text { Factor } \\
\text { variance }\end{array}$ & $\begin{array}{c}\% \text { of } \\
\text { total } \\
\text { variance }\end{array}$ & $\begin{array}{c}\text { Cumulative } \\
\text { Variance } \\
(\%)\end{array}$ & $\begin{array}{c}\text { Factor } \\
\text { variance }\end{array}$ & $\begin{array}{c}\% \text { of } \\
\text { total } \\
\text { variance }\end{array}$ & $\begin{array}{c}\text { Cumulative } \\
\text { Variance } \\
(\%)\end{array}$ & & \\
\hline 1 & 4.826 & 68.94 & 68.94 & 4.83 & 68.94 & 68.94 & BP1 & 0.72 \\
\hline 2 & 0.997 & 14.24 & 83.18 & & & & $\mathrm{BP} 2$ & 0.70 \\
\hline 3 & 0.468 & 6.68 & 89.86 & & & & BP3 & 0.71 \\
\hline 4 & 0.309 & 4.41 & 94.27 & & & & BP4 & 0.70 \\
\hline 5 & 0.205 & 2.93 & 97.21 & & & & BP5 & 0.73 \\
\hline 6 & 0.124 & 1.78 & 98.98 & & & & BP6 & 0.68 \\
\hline 7 & 0.071 & 1.02 & 100.00 & & & & BP7 & 0.59 \\
\hline
\end{tabular}

KMO test value $=0.82$, statistical reliability of $95 \%$ 
Relationship between Technological Capacity, Innovation Outcome and Business Performance of Small and Medium Enterprises in Ho Chi Minh City, Vietnam

Appendix3. Reliability analysis (Cronbach's Alpha) for TC, IO and BP

\begin{tabular}{|c|c|c|c|c|c|}
\hline & & & & & \\
\hline Cronba & a: 0.900 & Cronbach's & & Cronbach's & \\
\hline $\begin{array}{l}\text { Cronba } \\
\text { observe }\end{array}$ & $\begin{array}{l}\mathrm{a} \text { if } \\
\text { le deleted }\end{array}$ & $\begin{array}{l}\text { Cronbach's } \\
\text { deleted }\end{array}$ & ed variable & $\begin{array}{l}\text { Cronbach's } \\
\text { variable de }\end{array}$ & rved \\
\hline TC1 & .866 & IO1 & .898 & BP1 & .910 \\
\hline TC2 & .856 & $\mathrm{IO} 2$ & .858 & $\mathrm{BP} 2$ & .911 \\
\hline TC3 & .896 & IO3 & .872 & BP3 & .911 \\
\hline TC4 & .859 & IO4 & .894 & $\mathrm{BP} 4$ & .912 \\
\hline TC5 & .881 & IO5 & .881 & BP5 & .910 \\
\hline & & & & BP6 & .914 \\
\hline & & & & BP7 & .920 \\
\hline
\end{tabular}

\section{AUTHOR'S BIOGRAPHY}

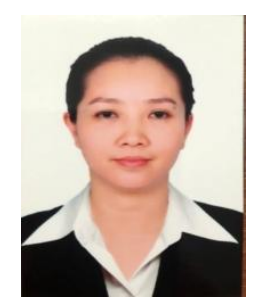

Le Diem Thu, is a Master of Human Resource Management and a Master of Public Policy. She is currently a researcher at the Center for Economics under the Southern Institute of Social Sciences, Vietnam Academy of Social Sciences, a research agency under the Government. Ms. Thu has many years of experience, research, teaching and many publications related to development economics associated with science and technology, human resource management and public policy issues in science and technology.

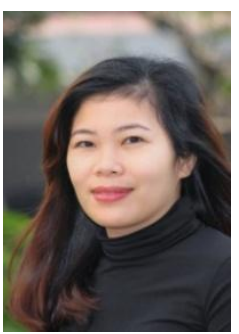

Vu Thi Phuong Giang, is a master and $\mathrm{PhD}$ student in economic law, majoring in intellectual property and science and technology. She currently works at the National Office of Intellectual Property, Ministry of Science and Technology - an agency be long to Government of Vietnam. She has many years of research, working and has made a number of publications on the angle of intellectual property, science and technology.

Citation: Thu Diem Le, MSc, Vu Thi Phuong Giang. " Relationship between Technological Capacity, Innovation Outcome and Business Performance of Small and Medium Enterprises in Ho Chi Minh City, Vietnam” International Journal of Humanities Social Sciences and Education (IJHSSE), vol 8, no.9, 2021, pp. 121-131. doi: https://doi.org/10.20431/2349-0381.0809012.

Copyright: (C) 2021 Authors. This is an open-access article distributed under the terms of the Creative Commons Attribution License, which permits unrestricted use, distribution, and reproduction in any medium, provided the original author and source are credited. 